\title{
Bezoar gástrico como complicación de banda gástrica en manejo de obesidad mórbida. Caso clínico
}

\author{
Claudio Cortés ${ }^{1,2}$, Claudio Silva ${ }^{2}$. \\ Gastric bezoar as complication \\ of gastric banding. Report of one case
}

Laparoscopic adjustable gastric banding (LAGB) is used for the management of morbid obesity. Phytobezoars are rarely reported as a complication of this operation and are usually extracted by endoscopic means. We report a 48 year-old male subjected to a gastric banding, that consulted for progressive dysphagia, six months after the operation. A barium meal x-ray examination demonstrated the presence of a bezoar that was dissolved in one week using papain. A control barium meal confirmed the disappearance of the bezoar (Rev Méd Chile 2008; 136: 1457-9).

(Key words: Bariatric surgery; Bezoars; Papain)

Recibido el 28 de diciembre, 2007. Aceptado el 24 de abril, 2008.

${ }^{1}$ Departamento de Imágenes, Clínica Alemana de Santiago. ${ }^{2}$ Centro de Imagenologia, Hospital Clinico de la Universidad de Chile. Santiago de Chile.

$\mathrm{S}_{\mathrm{q}}^{\mathrm{e}}$ define bezoar como "Concreción calculosa que suele encontrarse en las vías digestivas ... de algunos mamíferos" (Real Academia Española) ${ }^{1}$, identificándose en el humano como patología caracterizado por la acumulación de tejido foráneo en el tracto digestivo. Esta puede ser por fibras vegetales con digestión incompleta o fitobezoar (la más común), por cabello o tricobezoar (asociado habitualmente a patología psiquiátrica), y menos frecuentes, lactobezoar ${ }^{2}$ o bezoar por medicamentos ${ }^{3}$.

Los bezoares son de lento crecimiento y habitualmente asociados a factores predisponentes, que clásicamente había sido descrito en

Correspondencia a: Dr. Claudio Cortés A. Departamento de Imágenes, Clínica Alemana de Santiago, Vitacura 5951, Vitacura, Santiago, Chile. Fono: 56-2- 2101111.

E mail: claudiocort@Gmail.Com aquellos postgastrectomía, o post vagotomías, con trastorno o mal hábito deglutorio. Sin embargo, se han descrito casos en pacientes sometidos a procedimientos quirúrgicos de obesidad mórbida, como gastrectomía subtotal con Y de Roux ${ }^{4}$ y solo casos aislados de fitobezoar en pacientes con banda gástrica.

Presentamos un caso de fitobezoar gástrico en un paciente sometido a instalación de banda gástrica por vía laparoscópica y el manejo médico de su patología.

\section{CASO CLÍNICO}

Paciente de sexo masculino de 48 años, que al momento de someterse a instalación por vía laparoscópica de banda gástrica en mayo de 2006, tenía un índice de masa corporal de 35,3 (peso $102 \mathrm{kgs}$, talla 1,7 mt). En control de julio de 2006, había reducido peso a 90 kgs (IMC: 31,4), en 
buenas condiciones generales. A los siete meses de postoperatorio, inició disfagia progresiva de rápida evolución que incluso dificulta la ingesta de líquidos.

Se realizó evaluación radiológica con contraste baritado por sospecha de sobrecalibración de banda gástrica, donde se identificó defecto de llene ovoideo, y libre en reservorio (pouch) gástrico, con aspecto de bezoar.

El paciente rechazó la realización de extracción por vía endoscópica por lo que se realizó terapia médica administrando Papenzima ${ }^{\circledR}$ (Papaína) $10 \mathrm{mg}$ granulado vía oral cada $6 \mathrm{~h}$, con resolución parcial de los síntomas al quinto día y mejoría total al séptimo día. Se realizó control radiológico con estudio baritado al décimo día que revela disolución completa del bezoar.

\section{COMENTARIO}

Los bezoares gástricos se describieron clásicamente como complicación de cirugías resectivas gástricas o post vagotomías. Ellos se pueden asociar a complicaciones como obstrucción de intestino delgado, hemorragia digestiva alta, erosiones y úlceras gástricas e incluso perforación. Ahora, con la aparición de técnicas quirúngicas de banding gástrico para manejo de la obesidad mórbida, se ha producido un cambio en el perfil de aparición.
La técnica de banda gástrica laparoscópica, permite colocar un mecanismo restrictivo al volumen gástrico, el cual queda reducido a un pequeño porcentaje de su capacidad real. Ello trae asociado también un vaciamiento enlentecido, lo que determina estasis del contenido ingerido, elementos que favorecen la aparición de fitobezoares, como se ve en este paciente.

Se han descrito casos aislados de esta patología ${ }^{5-7}$ con periodos variables de aparición entre los 24 días a 6 años. Elementos que favorecen la aparición de estos bezoares, es la ingesta de alimentos ricos en fibra o cáscaras ${ }^{5}$, o laxantes basado en fibra de metilcelulosa7 ${ }^{7}$. Como elementos personales propicios para ello, es el mal hábito o mecánica de masticación con deglución de alimentos parcialmente preparados y un bolo inadecuado.

Se han propuesto múltiples terapias para el manejo del bezoar gástrico, desde la fragmentación y extracción por endoscopia, cirugía abierta, hasta casos anecdóticos de disolución con bebidas carbonatadas como Coca-Cola ${ }^{\circledR 8,9}$. Si bien está descrita también el uso de enzimas proteolíticas como papaina o desintegradoras como celulasa ${ }^{10}$, no tenemos conocimiento de algún caso de bezoar gástrico en paciente con banda gástrica manejada médicamente, dado que habitualmente se realiza por extracción endoscópica. Surge así como posibilidad terapéutica en este grupo de pacientes.

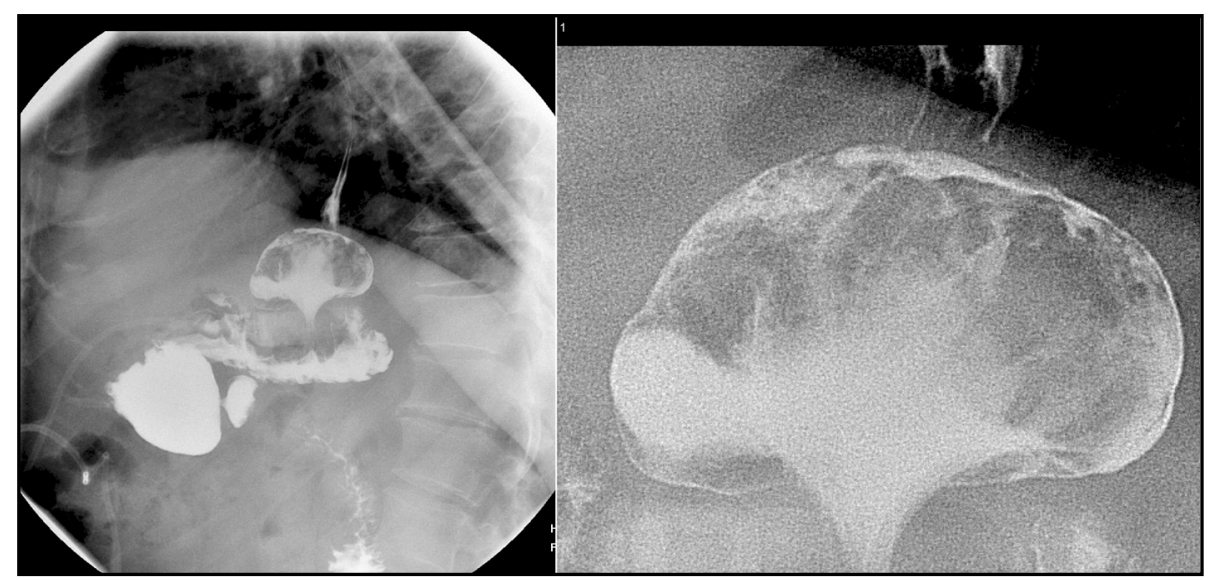

Figuras 1 y 2. Radiografía de esófago-estómago y duodeno con material baritado diluido que revela presencia de banda gástrica bien situada, con defecto de llene ovoideo y libre en reservorio gástrico ("pouch"), con aspecto de corresponder a un bezoar. 


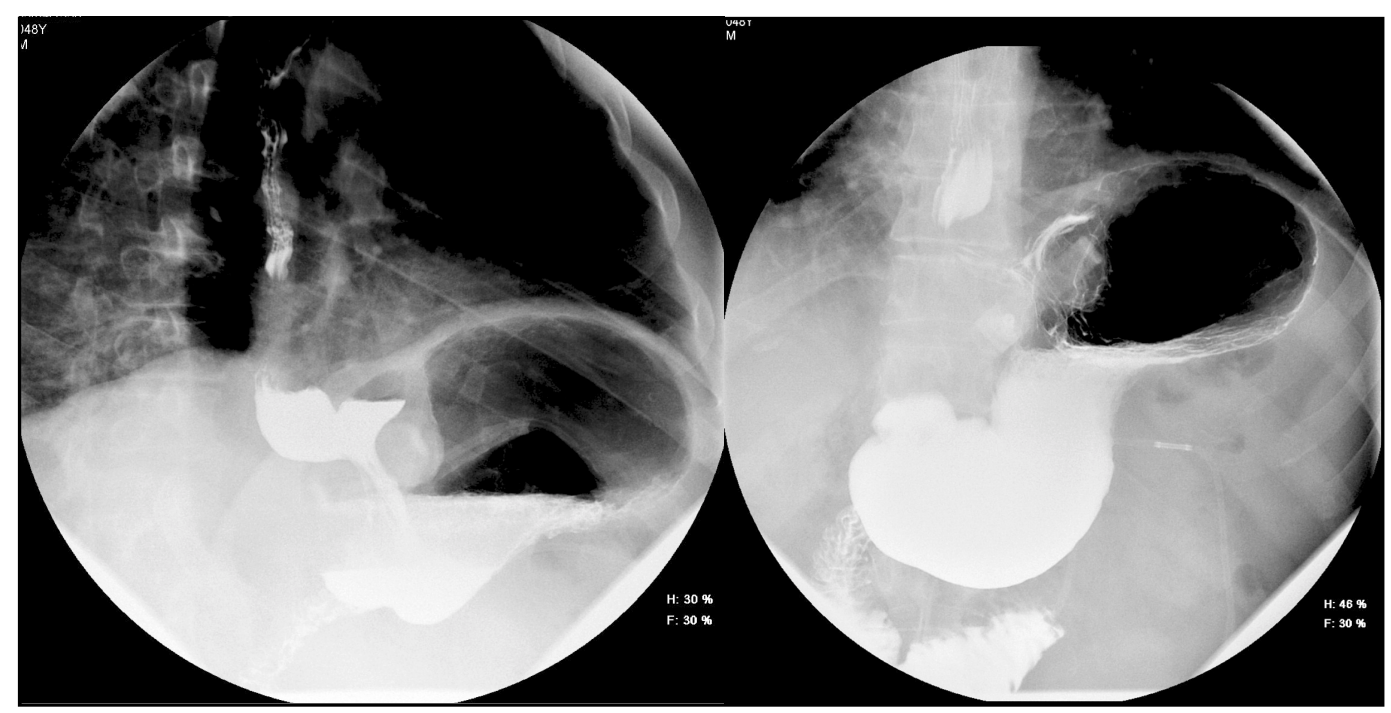

Figuras 3 y 4. Control con radiografía de esófago-estómago-duodeno al décimo día posterior a la ingesta de papaína, que revela total disolución del bezoar.

\section{REFERENCIAS}

1. Diccionario de la Real Academia Española. (http:// www.rae.es/ ) Acceso online: 3/Enero/2007.

2. Graham RJ, Stein P. Gastric outlet obstruction in an infant: lactobezoar. Am J Emer Med 2007; 25: 98-9

3. Taylor JR, Streetman DS, Castle SS. Medication Bezoars: A Literature Review and Report of a Case. Ann Pharmacother 1998; 32: 940-6.

4. Zapata R, CASTILO F, Córdova A. Bezoar gástrico como complicación de la cirugía de obesidad mórbida. Caso clínico y revisión de la literatura. Gastroenterol Hepatol 2006; 29: 77-80.

5. White NB, Gibbs KE, Goodwin A, Teixeira J. Gastric Bezoar Complicating Laparoscopic Adjustable Gastric Banding and Review of Literature. Obes Surg 2003; 13: 948-50.
6. Veronew A, Ranieri R, Laneri M, Montorsi M, Bianchi P, Cosentino F et AL. Gastric Bezoars after Adjustable Gastric Banding. Obes Surg 2004; 14: 796-7.

7. Herrie F, Peters T, Lang C, von Fluee M, Kern B, PeterL R. Bolus Obstruction of Pouch Outlet by a Granular Bulk Laxative after Gastric Banding. Obes Surg 2004; 14: 1022-4.

8. Sechopoulo P, Robotis J, Rokkas T. Gastric bezoar treated endoscopically with a carbonated beverage: case report. Gastrointest Endoscopy 2004; 60: 662-4.

9. Chung YW, Han DS, Park YK, Son BK, Paik CH, Jeon YC ET AL. Huge gastric diospyrobezoars successfully treated by oral intake and endoscopic injection of Coca-Cola. Dig Liv Dis 2006; 38: 515-7.

10. Dwivedi AJ, Chahin F, Agrawal S, Patel J, Khald M, LAKRA Y. Gastric phytobezoar: treatment using meat tenderizer. Dig Dis Sci 2001; 46: 1013-5. 